\title{
BDA Honours and Awards recipients announced
}

Twenty individuals are being celebrated in the latest round of the prestigious BDA Honours and Awards, for their outstanding achievements, their commitment to the British Dental Association (BDA) and their work for the dental profession.

Recipients come from all sections of the profession: from general practice through to community and hospital dentistry, and across the four nations. The BDA is proud to honour these people and the work they have done.

\section{Fellowship Medal}

Dr Colette Bridgman, Laurie Jacobs, Dr Nigel Monaghan, Dr Graham Smith, Dr Sandra White.

\section{Life Membership}

Michael Cranfield, Allan Franklin,

Professor David Hussey.

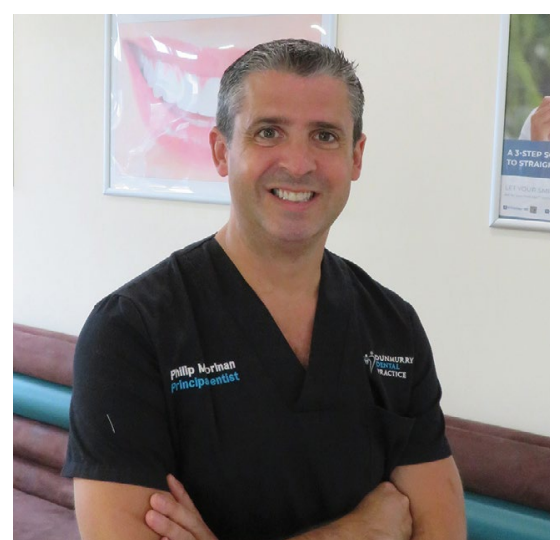

Philip McLorinan

\section{Roll of Distinction}

Maria Morgan, Penny Whitehead.

\section{Certificate of Merit for Services to the}

\section{Association}

Tom Bysouth, Fiona Gray, Philip McLorinan, Sue Page, Kiran Shankla, Tim Vernon, Arabella Yelland.

\section{Certificate of Merit for Services to the} Profession

Lauren Harrhy, Sagar Shah.

\section{Joy Harrild Award}

Carly Fraser.

Roz McMullan, Chair of the BDA's Honours and Awards Committee, said: 'I am delighted to see these people honoured for their hard work and commitment to dentistry. Through these times of immense challenge and change,

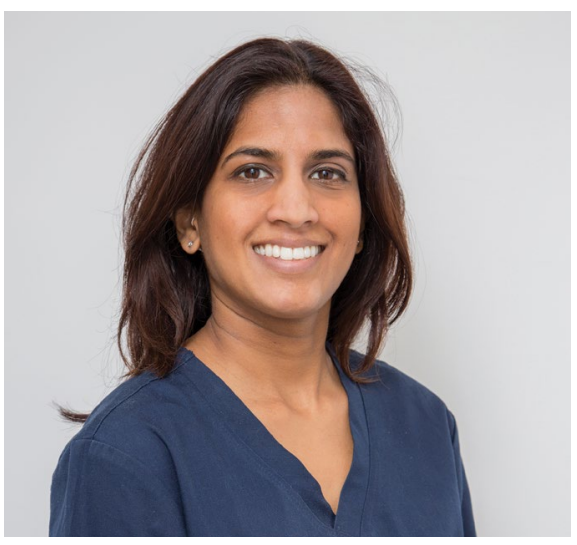

Kiran Shankla we are proud to be able to highlight the work of those who have gone above and beyond, making our profession better. We are proud to showcase those who have supported our causes, gone over and above for the profession, and/or given exemplary patient care.

'During 2021/2022, we want to find dentists who have shown a commitment to advancing dentistry. We strongly encourage nominations from all areas of the profession - please consider putting forward a colleague/s who you think deserve recognition for what they do.'

You can find out more and nominate via: https://www.bda.org/about-the-bda/ honours-and-awards/Pages/default. aspx. The deadline for the next round of nominations is 27 May 2022. Nominations for the Joy Harrild Award for Young Dentists should be submitted by 29 April 2022.

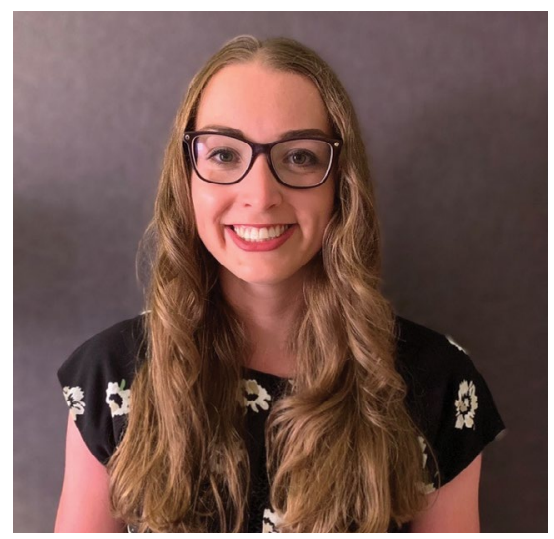

Carly Fraser

\section{Share your experiences of working in dentistry}

The British Dental Association (BDA) is calling on general dental practitioners, community dentists and those working in the public dental service to share their experiences of working in UK dental practice.

Your response will shape the vital work the BDA undertakes on your behalf. You can provide the BDA with a unique insight into the pressures currently facing the workforce and help inform the evidence the Association submits to the Doctors and Dentists
Review Body that makes recommendations on dentists' pay.

Share thoughts on your motivation, job satisfaction, morale and wellbeing as well as your working patterns and hours, future career intentions and other issues important to your sector.

It takes just 10-15 minutes to complete the survey and all members who complete the survey will go into a draw to win a $£ 100$ gift card.

Your information will remain anonymous and confidential with no personal information or details passed on to any third parties.

If you have received an email from the BDA inviting you to take part, please complete the survey today by clicking on the personalised link shown in the email entitled 'Share your views: survey of UK GDPs' or 'Share your views: survey of UK CDS/PDS'.

If you have any questions or would like more information about this research, please contact the Research Team at research@bda.org. 